\title{
A DOUTRINA DA "ECONÔMICA" NA CONCEPÇÃO ESCRAVISTA DE ANTONIL. UMA LEITURA DE CULTURA E OPULÊNCIA DO BRASIL
}

\author{
MATTEO GIULI \\ UNIVERSIDADE DE BRASÍLIA (UNB)
}

\begin{abstract}
RESUMO: Analisando as ideias do jesuíta italiano Antonil sobre a condução dos engenhos açucareiros no Brasil colonial, este artigo se propõe a evidenciar a presença no maior trabalho dele - o famoso tratado Cultura e opulência do Brasil - de princípios éticos e políticos atribuíveis a uma doutrina nascida no contexto da antiga tradição grega e latina: a doutrina da "econômica", expressão de uma disciplina que, diferentemente da pura economia, não se ocupa apenas dos problemas da produtividade e da riqueza. Os princípios da "econômica" aparecem, sobretudo, na primeira parte deste tratado, que analisa as relações entre senhores de engenho e escravos. Nesse sentido, então, a obra de Antonil representa uma manifestação original no contexto da literatura lusófona da Idade Moderna.
\end{abstract}

PALAVRAS-CHAVE: Jesuítas; Engenho; Escravos; "Econômica".

ABSTRACT: By analyzing the ideas of the Italian Jesuit Antonil on the conduct of sugar mills during the colonial Brazil, this article aims to highlight the existence in his greatest work - the famous treaty Cultura e Opulência do Brasil - of ethical and political principles attributable to a doctrine born in the context of ancient Greek and Latin tradition: the doctrine of "econômica", expression of a discipline that, unlike pure economy, takes into account not only problems related to productivity and wealth. The principles of "econômica" appear especially in the first part of this treaty, which analyzes the relationship between sugar plantations owners and slaves. Therefore, the work of Antonil is an original manifestation in the context of the Early Modern Lusophone literature.

KEYWORDS: Jesuits; Sugar cane mill; Slaves; "Oikonomika". 
"Os escravos saõ as mãos, \& os pés do senhor do engenho": é com esta metáfora organicista que o jesuíta italiano André João Antonil (pseudônimo de Giovanni Antonio Andreoni) descreve a função exercida pelo regime escravista no sistema de produção açucareira do Brasil colonial; uma função fundamental, pois, na opinião do religioso, sem os escravos "naõ é possivel fazer, conservar, \& aumentar fazenda, nem ter engenho corrente ${ }^{\prime 1}$. Trata-se de considerações bastante conhecidas, que se encontram na primeira parte de Cultura $e$ opulência do Brasil, o famoso tratado que este jesuíta tentou publicar em 1711 pela Oficina Real Deslandesiana de Lisboa, sem conseguir, contudo, nesse propósito, por causa das restrições impostas pelo governo português; logo depois de ter sido impressa, esta obra foi censurada e destruída por ordem de Dom João $\mathrm{V}$ após proposta do Conselho Ultramarino, sendo redescoberta pela historiografia brasileira só a partir do século XIX. Muitos estudiosos já falaram das complexas vicissitudes editoriais desse texto, assim como da enigmática identidade do seu autor, que se assinou como "O Anonymo Toscano"2.

Trata-se, com certeza, de uma obra fundamental, que por muito tempo permaneceu uma fonte primária para a reconstrução histórica da sociedade colonial brasileira e, sobretudo, da economia das regiões nordestinas; uma obra que não se limita à descrição das principais atividades produtivas do Brasil entre os séculos XVII e XVIII (cultivo de açúcar e tabaco, mineração de ouro, criação de gado e venda de couro), mas que também analisa em pormenor as relativas técnicas de execução, oferecendo ao mesmo tempo dicas pedagógicas de bom comportamento, sobretudo com respeito aos senhores de engenho ${ }^{3}$. Trata-se,

\footnotetext{
${ }^{1}$ ANTONIL, André João. Cultura e opulência do Brasil por suas drogas e minas. Com varias noticias curiosas do modo de fazer o Assucar; plantar \& beneficiar o Tabaco; tirar Ouro das Minas; \& descubrir as da Prata; e dos grandes emolumentos que esta Conquista da America Meridional dá ao Reyno de Portugal com estes \& outros generos, \& Contratos Reaes. Lisboa: Officina Real Deslandesiana, 1711, p. 22. No curso do presente artigo, as citações tiradas desta edição de Cultura e opulência do Brasil manterão a própria grafia originaria.

2 Sobre a história editorial desta obra, ver a introdução de Andrée Mansuy Diniz Silva a ANTONIL, André João. Cultura e Opulência do Brasil por suas Drogas e Minas. São Paulo: Edusp, 2007, p. 25-64. A causa principal da sua destruição, apenas duas semanas depois da última licença concedida pelo Tribunal do Desembargo do Paço, em Lisboa, deve ser relacionada com as detalhadas informações que Antonil ofereceu sobre a descoberta das minas no Brasil e a extração do ouro. A primeira reedição integral da obra, cheia de erros e omissões, saiu à luz em 1837, impressa pela tipografia Villeneuve do Rio de Janeiro. Duas importantes reedições são aquelas de 1923 e 1967, publicadas em São Paulo, respectivamente pela Companhia Melhoramentos e pela Companhia Editora Nacional, as quais incluem os comentários de Affonso Taunay e Alice Canabrava. Cultura e opulência do Brasil foi traduzida também em francês (em 1968, por Andrée Mansuy Diniz Silva) e inglês (em 2012, por Charles Boxer e Timothy Coates, com o título Brazil at the Dawn of the Eighteenth Century). A solução do enigma relativo à verdadeira identidade de Antonil foi oferecida por Capistrano de Abreu no final do século XIX; ele o identificou com o jesuíta italiano Giovanni Antonio Andreoni, que nasceu em Lucca (Toscana) em 1649, chegou ao Brasil em 1681 e faleceu em Salvador da Bahia em 1716: ver o "estudo biobibliográfico" de Affonso Taunay em ANTONIL, André João. Cultura e opulência do Brasil. 2. ed. São Paulo: Edições Melhoramentos, 1976, p. 23-59.

${ }^{3}$ CHAVES, Marta; FAUSTINO, Rosângela. A educação no pensamento de Antonil: algumas reflexões sobre a obra Cultura e Opulência do Brasil. Acta Scientiarum: human and social sciences. Maringá, v. 25, n. 1, p. 95-103, 2003.
} 
então, de um texto profundamente original no contexto da literatura lusófona relativa ao Brasil, pois as obras escritas e/ou publicadas sobre temáticas relacionadas à economia e particularmente à agricultura, ainda no início do século XVIII, permaneciam geralmente descritivas ou narrativas, sendo ocasionais as advertências técnicas e educativas nelas oferecidas ${ }^{4}$.

\section{Cultura e Opulência do Brasil: um tratado de "econômica"}

Cultura e opulência do Brasil representa um texto inovador, que pode ser classificado como um verdadeiro tratado de "econômica", disciplina que deve ser bem distinguida da economia: esta, a pura ciência da produção dos bens de consumo, surgida no curso do século XVIII, caracteriza-se por ter como objeto de estudo uma esfera única e autônoma - a da riqueza - com respeito a outros aspectos fundamentais da sociedade e da vida dos homens; a "econômica", baseando-se na tradição cultural dos antigos gregos e latinos, se apresenta em vez como uma doutrina interessada a todo problema - ético e político também - relacionado ao governo de qualquer entidade coletiva, ou seja, à administração de uma casa, uma família, um patrimônio ou, ainda, como no caso de Cultura e opulência do Brasil, um engenho ${ }^{5}$. Numa ótica paternalística, os leitores para os quais este tratado foi pensado (senhores de engenho e lavradores) não eram só instruídos sobre as questões técnicas da agricultura (açúcar, tabaco) e da criação (gado), mas, também, sobre o estilo de vida que eles tinham que adotar, sobre suas relações familiares e sobre como deveriam gerir seus próprios empregados.

Mais especificamente, Cultura e opulência do Brasil constitui uma manifestação importantíssima - e talvez, na literatura lusófona, a única ${ }^{6}$ - de uma tradição pedagógica e técnico-didática característica da Antiguidade clássica, representada exemplarmente pelos textos dos gregos Xenofonte e Teofrasto, assim como dos latinos Varrão, Plínio (o Velho), Columela e Catão (o (ensor) ${ }^{7}$. Em particular, uma das maiores obras deste último, intitulada De agri

\footnotetext{
${ }^{4}$ Introdução de Andrée Mansuy Diniz Silva a ANTONIL, André João. Cultura e opulência do Brasil por suas drogas e minas. São Paulo: Edusp, 2007, p. 35.

${ }^{5}$ A "econômica" antiga se baseava na centralidade atribuída a casa (oikos, origem da palavra oikonomia), às suas atividades produtivas e às sua relações internas, colocando todas as transações comerciais de tipo lucrativo na esfera da assim chamada "crematística", considerada execrável: ver BRUNNER, Otto. Neue wege der verfassungs - und sozialgeschichte. Göttingen: Vandenhoeck \& Ruprecht, 1980 (Per una nuova storia costituzionale e sociale. 2. ed. Milano: Vita e Pensiero, 2000, p. 117-164).

${ }^{6}$ Introdução de Andrée Mansuy Diniz Silva a ANTONIL, André João. Cultura e opulência do Brasil por suas drogas e minas. São Paulo: Edusp, 2007, p. 35.

7 BIVAR MARQUESE, Rafael de. Administração \& escravidão. Ideias sobre a gestão da agricultura escravista brasileira. São Paulo: Hucitec-Fapesp, 1999, p. 55-62; BIVAR MARQUESE, Rafael de; DUARTE JOLY, Fábio. Panis, disciplina, et opus servo: the Jesuit Ideology in Portuguese America and Greco-Roman Ideas of Slavery. In: DAL LAGO, Enrico; KATSARI,
} 
cultura, tinha assumido a função de um verdadeiro manual de comportamento para os patrícios romanos que fossem proprietários agrícolas e donos de casa (patres familias), exaltando a sua honestidade moral e sabedoria técnica; uma obra que visava enobrecer, sobretudo, a tradicional vocação rústica dos cidadãos da antiga Roma republicana, frente à afirmação das novas riquezas baseadas nos comércios e no empréstimo de dinheiro, assim como legitimar a superioridade ética e educativa da agricultura com respeito às outras atividades econômicas.

Talvez inspirado pela leitura de alguns desses clássicos, Antonil se moveu na mesma direção, denunciando na terceira parte da sua obra as consequências nefastas, sob vários pontos de vista, da descoberta do ouro no Brasil. Na ótica paternalista do jesuíta italiano, baseada nos princípios da "econômica", era urgente defender a centralidade das atividades agrícolas tradicionais - a produção de açúcar e tabaco - frente à nova sedução enganadora representada pela mineração, que ameaçava perigosamente o equilíbrio social de todo o sistema colonial ${ }^{8}$. Fundando-se na tradição literária clássica, então, Cultura $e$ opulência do Brasil se relaciona estreitamente aos maiores tratados de agronomia publicados na Europa a partir da época renascentista, tais como os do espanhol Gabriel Alonso de Herrera, do italiano Agostino Gallo e, ainda mais, dos franceses Charles Estienne e Olivier de Serres, este último autor do famoso Théâtre d'Agriculture et mesnage des champs, editado várias vezes no curso do século XVII ${ }^{9}$.

Isso é verdade, sobretudo, em relação à primeira parte do texto de Antonil - a parte mais longa e articulada - dedicada ao inteiro processo produtivo do açúcar, analisado num estilo barroco e prolixo, muito diferente daquele mais simples do resto da obra. Esta primeira parte é também a única que apresenta um título próprio - "Cultura e Opulencia do Brasil na Lavra do Assucar. Engenho real moente \& corrente" - assim como um breve sumário e um próprio prefácio, definido "Proemio" pelo autor. De acordo com Andrée Mansuy Diniz Silva, tais características sugerem que o projeto inicial do jesuíta italiano fosse, muito provavelmente, o de escrever apenas um tratado sobre a produção açucareira, naquela época ainda a maior fonte de renda da economia colonial portuguesa; só num segundo momento, frente ao grande impacto da recente descoberta das minas no Brasil, ele decidiu expandir os próprios horizontes, analisando criticamente as várias transformações econômicas e sociais relacionadas à extração aurífera, uma atividade que em sua opinião estimulava perigosamente a "insaciável cobiça dos homens"10.

Constantina (Org.). Slave Systems. Ancient and Modern. Cambridge: Cambridge University Press, 2008, p. 214-230.

${ }^{8}$ ANTONIL, André João. Cultura e Opulencia do Brasil por suas drogas e minas. Lisboa: Officina Real Deslandesiana, 1711, p. 139-143, 179-181. A este respeito, ver também THEODORO DA SILVA, Janice. André João Antonil. Cultura e opulência do Brasil. In: DANTAS MOTA, Lourenço (Org.). Introdução ao Brasil. Um banquete no trópico. V. 1. São Paulo: Senac, 1999, p. 55-73.

9 BOULAINE, Jean; MOREAU Richard. Olivier de Serres et l'évolution de l'agriculture. Paris: L'Harmattan, 2002, p. 29-58.

${ }^{10}$ Introdução de Andrée Mansuy Diniz Silva a ANTONIL, André João. Cultura e opulência do Brasil por suas drogas e minas. São Paulo: Edusp, 2007, p. 40-42, 47-51. Sobre a importância da produção açucareira e da mineração aurífera na história do Brasil, ver os clássicos: BOXER, Charles Ralph. The golden age of Brazil. 1695-1750. Growing Pains of a Colonial Society. 


\section{As dicas para os senhores: como administrar os engenhos segundo Antonil}

Antonil redigiu a primeira parte de Cultura e opulência do Brasil na última década do século XVII, logo depois ter passado uns 10 dias no engenho de Sergipe do Conde, propriedade jesuítica nos arredores da Bahia; este lugar, que no "Proemio" ele definiu como sendo "taõ celebrado, \& quasi rey dos engenhos reaes", Ihe ofereceu um excelente campo de observação e de análise, assim como a possibilidade de encontrar muitas informações técnicas sobre o cultivo da cana.

Dos três livros que compõem a primeira parte (cada um com 12 capítulos), o primeiro é, talvez, o mais interessante; enquanto nos outros Antonil trata dos assuntos técnicos e das questões práticas referentes ao inteiro ciclo produtivo do açúcar, no primeiro ele descreve a figura do senhor de engenho e elenca as qualidades que Ihe são necessárias para virar um rico produtor, estabelecendo, nesse sentido, uma comparação de status entre oligarquia açucareira e fidalguia portuguesa: "bem se póde estimar no Brasil o ser senhor de engenho, quanto proporcionadamente se estimaõ os titulos entre os fidalgos do Reyno", pois o "titulo de senhor de engenho", mesmo sem conferir a nobreza, oferece "acrecentamento de estimaçaõ, \& de crédito", trazendo consigo "o ser servido, obedecido, \& respeitado"11.

De acordo com Antonil, ao senhor de engenho é pedido um tipo particular de atitude, em relação ao seu papel no contexto colonial: deve saber governar a própria família, atender à educação dos próprios filhos e administrar os gastos ordinários da casa, usando sempre parcimônia e moderação ("mao é ter nome de avarento" - explica o jesuíta - "mas naõ é gloria digna de louvor o ser prodigo"12); deve ter "capacidade e prudência" na escolha dos empregados (feitores, mestres, soto-mestres, ajudantes, purgadores, caixeiros, fiscais e escravos, um time "que nos mayores engenhos passa o numero de cento \& cincoenta, \& duzentas peças" ${ }^{13}$ ), atribuindo uma importância fundamental à figura do "capellaõ", encarregado "de dizer missa na capella do engenho nos domingos, \& dias santos", assim como de ensinar "tudo o que pertence á vida

Berkeley: University of California Press, 1962, p. 30-60; RUSSELL-WOOD, Anthony John. Colonial Brazil: the gold cycle, c. 1690-1750. In: BETHELL, Leslie (Org.). The Cambridge History of Latin America. II. Colonial Latin America. Cambridge: Cambridge University Press, 1984, p. 547-600; RIBEIRO, Darcy. O povo brasileiro. A formação e o sentido do Brasil. São Paulo: Companhia das Letras, 1995, p. 245-268; FREYRE, Gilberto. Casa-grande \& senzala. Formação da família brasileira sob o regime da economia patriarcal. 48. ed. São Paulo: Global Editora, 2003, p. 64-155.

${ }^{11}$ ANTONIL, André João. Cultura e opulência do Brasil por suas drogas e minas. Lisboa: Officina Real Deslandesiana, 1711, p. 1-4.

${ }^{12}$ Ibid., p. 29-30. Este trecho de Antonil recorda o canto da Divina comédia (Inferno, VII, 4042) onde o poeta Dante Alighieri descreve as penas infernais sofridas pelos avarentos e pelos pródigos, os quais em vida foram pecadores incontinentes, não sabendo gastar com medição as próprias riquezas ("che con misura nullo spendio fercl").

${ }^{13}$ ANTONIL. Op. cit., p. 1-4. 
christaã"14; deve ter boa "agencia" com os próprios lavradores e com os vizinhos, comportando-se com "urbanidade, \& primor"15; e, sobretudo, deve administrar com "capacidade e prudência" os próprios negócios, respeitando os prazos estabelecidos, pagando com pontualidade as dívidas e adotando, mais geralmente, uma atitude digna de confiança ${ }^{16}$.

Antonil trata também da atenção que o senhor deve ter ao escolher e comprar as terras para o cultivo da cana, assim como do ciúme com o qual deve conservar os documentos comprobatórios dos seus direitos de propriedade, papéis fundamentais frente às eventuais reivindicações dos lavradores "que tem partidos arrendados em terras do mesmo engenho"17. Nesse sentido, tendo consciência de que "o fim do tempo do arrendamento" possa se transformar num "principio de demandas eternas", o jesuíta propõe a redação de "huma fórmula, ou nota" de contrato escrita por letrados "dos mais experimentados", para que alguém "de lavrador se naõ faça logo senhor"18. Essa recomendação reflete a excelente cultura jurídica de Antonil, que estudou Direito por três anos na Universidade de Perúgia, quando ainda estava na Itália. Ela é muito significativa porque mostra a existência, também no Brasil colonial, de um problema bastante difundido nas sociedades do Antigo Regime, onde os títulos de propriedade ficavam frágeis, precários e frequentemente contestados frente à força jurisdicional da ação (então do trabalho), a qual tinha a capacidade de criar novas prerrogativas jurídicas e modificar hierarquias sociais pré-existentes $^{19}$.

\footnotetext{
${ }^{14}$ Ibid., p. $10-14$.

${ }^{15}$ Ibid., p. 7-10.

${ }^{16}$ Ibid., p. 33-36: "o credito de hum senhor de engenho", cuja conservação "é o melhor cabedal dos que se prezaõ de honrados" - escreve Antonil -, se baseia "na sua verdade, isto é, na pontualidade, \& fidelidade em guardar as promessas". Sobre a confiança como elemento básico para o funcionamento das atividades econômicas e comerciais no Antigo Regime, ver: FONTAINE, Laurence. L'économie morale. Pauvreté, crédit et confiance dans l'Europe préindustrielle. Paris: Gallimard, 2008, p. 277-307; PRODI, Paolo. Settimo non rubare. Furto e mercato nella storia dell'Occidente. Bologna: il Mulino, 2009, p. 121-125.

${ }^{17}$ ANTONIL. Op. cit., p. 5-7.

${ }^{18}$ Ibid.: para Antonil é fundamental que os senhores de engenho consigam evitar demandas e pleitos, que representam "huma continua desenquietaçaõ da alma, \& hum continuo sangrador de rios de dinheiro, que vay a entrar nas casas dos advogados, solicitadores, \& escrivaens, com pouco proveito de quem promove o pleito, ainda quando alcança, depois de tantos gastos, \& desgostos, em seu favor a sentença".

${ }^{19}$ Ibid.: "Nem deixe os papeis \& as escrituras que tem na caixa da mulher, ou sobre huma meza exposta ao pó, ao vento, á traça, \& ao copim; para que depois naõ seja necessario mandar dizer muitas missas a Santo Antonio, para achar algum papel importante que desappareceo, quando houver mister exhibillo. Porque lhe acontecerá que a criada ou serva tire duas ou tres folhas da caixa da senhora, para emburulhar com ellas o que mais lhe agradar; \& o filho mais pequeno tirará tambem algumas da meza, para pintar caretas, ou para fazer barquinhos de papel em que naveguem moscas \& grillos; ou finalmente o vento fará que voem fóra da casa sem pennas". Sobre a força jurisdicional da ação - um dos temas mais debatidos pelas Ciências Sociais aplicadas ao Estudo do Direito - ver COSTA, Pietro. Iurisdictio. Semantica del potere politico nella pubblicistica medievale (1100-1433). Giuffrè: Milano, 2002, p. 95-184.
} 


\section{As dicas para os senhores: como gerir os escravos segundo Antonil}

Entre as advertências contidas no primeiro livro da primeira parte de Cultura e opulência do Brasil, aquelas que Antonil oferece com maior abundância se encontram no capítulo IX, um dos mais longos e densos da obra, intitulado "Como se há de haver o Senhor do Engenho com seus Escravos". Nele, é apresentada uma análise perspicaz sobre as obrigações recíprocas baseadas nos princípios da "econômica" - que ligam essas duas figuras opostas do sistema produtivo açucareiro; uma análise feita misturando colonialismo mercantilista e moral cristã, num contexto onde os jesuítas também possuíam engenhos e escravos ${ }^{20}$. Trata-se de páginas muito significativas, visto que a sua redação ocorreu nos anos seguintes aos dramáticos eventos da Guerra dos Palmares.

A abertura desse capítulo reflete, ela também, uma concepção organicista e hierárquica da sociedade colonial, evidenciada pela metáfora fisiológica, pertencente à antiga tradição grega e latina, entre a função instrumental dos escravos e a função instrumental das partes terminais do corpo humano, ou seja, as mãos e os pés ${ }^{21}$. Antonil começa descrevendo as características físicas e psicológicas dos escravos que chegam da África, para advertir os senhores de engenho que a sua escolha, compra e distribuição precisam de muita atenção, pois se trata de uma passagem decisiva para o bom rendimento da produção açucareira:

E porque comummente saõ de Naçoens diversas, \& huns mais boçaes que outros, \& de forças muito differentes, se ha de fazer a repartiçaõ com reparo, \& escolha, \& naõ às cegas. Os que vem para o Brasil saõ Ardas, Minas, Congos, de Saõ Thomé, de Angola, de Cabo Verde, \& alguns de Moçãbique, que vem nas naos da India. Os Ardas \& os Minas saõ robustos. Os de Cabo Verde $\&$ de Saõ Thomé saõ mais fracos. Os de Angola creados em Loanda saõ mais capazes de aprender officios mecanicos que os das outras partes já nomeadas. Entre os Congos ha tambem alguns bastantemente industriosos, \& bons, naõ sómente para o serviço da canna, mas para as officinas, \& para o meneo da casa. Huns chegaõ ao Brasil muito rudes, \&

\footnotetext{
${ }^{20}$ SCHWARTZ, Stuart B. Segredos internos. Engenhos e escravos na sociedade colonial, 15501835. São Paulo: Companhia das Letras, 1988, p. 99-130; MÜLLER, Sálvio Alexandre. A Natureza Brasileira segundo dois Cronistas do Período Colonial. Revista Brasileira de História. São Paulo, v. 11, n. 21, p. 199-213, 1991; ALDEN, Dauril. The making of an enterprise. The Society of Jesus in Portugal, Its Empire, and Beyond. 1540-1750. Stanford: Stanford University Press, 1996, p. 528-570; ASSUNÇÃO, Paulo de. A escravidão nas propriedades jesuíticas. Entre a caridade cristã e a violência. Acervo. Revista do Arquivo Nacional. Rio de Janeiro, v. 15, n. 1, p. 115-132, 2002.

${ }^{21}$ Esta metáfora, comparando o corpo social ao corpo humano, além de recordar a fábula de Esopo sobre a barriga e os membros, se relaciona de perto ao apólogo contado pelo senador romano Menênio Agripa frente à plebe em revolta, do qual fala o historiador latino Tito Lívio ( $A b$ Urbe condita libri CXLII, II, 32).
} 
muito fechados, \& assim continuaõ por toda a vida. Outros em poucos annos saem ladinos, \& espertos, assim para aprenderem a doutrina christãa, como para buscarem modo de passar a vida, \& para se Ihes encomendar hum barco, para levarem recados, \& fazerem qualquer diligencia das que costumaõ ordinariamente occorrer ${ }^{22}$.

Conformando-se a uma opinião bastante difundida nas sociedades coloniais, Antonil afirma preferir os escravos crioulos, já nascidos no Brasil, e sobretudo os mulatos, bons "para qualquer officio", mesmo se "muitos delles, usando mal do favor dos senhores, saõ soberbos, \& viciosos" ${ }^{\prime 23}$. O problema é gerir a sua exuberância, pois "com aquella parte de sangue de brancos que tem nas veas, \& tal-vez dos seus mesmos senhores", os mulatos "os enfeitiçaõ de tal maneira que alguns tudo Ihes sofrem, tudo Ihes perdoaõ"; é por isso, por causa dessa atitude submissa e complacente de muitos senhores, que para 0 Antonil existe o provérbio segundo o qual "o Brasil é Inferno dos negros, Purgatorio dos brancos, \& Paraiso dos mulatos, \& das mulatas", tendo estes últimos "a melhor sorte" e "todos os mimos"24.

Além dessas considerações pitorescas, as maiores preocupações do jesuíta italiano se relacionam com a catequese dos escravos, sendo muitas as críticas exprimidas com respeito àqueles senhores que manifestamente se desinteressam por este problema:

Outros saõ tam pouco cuidadosos do que pertence á salvaçaõ dos seus escravos, que os tem por muito tempo no cannaveal ou no engenho, sem bautismo; \& dos bautizados muitos naõ sabem quem é o seu Creador; o que haõ de crer; que ley haõ de guardar; como se haõ de encomendar a Deos; a que vaõ os christãos á Igreja; porque adoraõ a hostia consagrada; que vaõ a dizer ao Padre, quando ajoelhaõ, \& Ihe fallaõ aos ouvidos; se tem alma, \& se ella morre, \& para onde vay quando se aparta do corpo [...] dizem os senhores que estes naõ saõ capazes de aprender a confessarse, nem de pedir perdaõ a Deos, nem de rezar pelas contas, nem de saber os dez Mandamentos: tudo por falta de ensino, \& por naõ considerarem a conta grande que de tudo isto haõ de dar a Deos; pois (como diz Saõ Paulo) sendo christãos, \& descuidando-se dos seus escravos, se haõ com elles peyor do que se fossem infieis ${ }^{25}$.

\footnotetext{
${ }^{22}$ ANTONIL. Op. cit., p. 23. Sobre os escravos africanos e o tráfico negreiro, ver os clássicos: SCHWARTZ, Stuart B. Segredos internos. Engenhos e escravos na sociedade colonial, 15501835. São Paulo: Companhia das Letras, 1988, p. 213-220; DAVIDSON, Basil. Black mother. The Years of the African Slave Trade. New York: Little, Brown and Company, 1961, p. 106-131; POLANYI, Karl. Dahomey and the Slave Trade. An Analysis of an Archaic Economy. Seattle: University of Washington Press, 1966, p. 119-157; VERGER, Pierre. Flux et reflux de la traite des nègres entre le Golfe de Bénin et Bahia de Todos os Santos du XVII au XIX siècle. Paris Den Haag: École Pratique des Hautes Études - Mouton\&C., 1968, p. 27-163; MAURO, Frédéric. Le Portugal, le Brésil et I'Atlantique au XVII siècle (1570-1670). Paris: Fondation Calouste Gulbenkian, 1983, p. 275-283.

${ }^{23}$ ANTONIL. Op. cit., p. 23.

${ }^{24}$ Ibid., p. 24.

${ }^{25}$ Ibid., p. 25.
} 
Como jesuíta com importantes cargos na Província da Bahia, é claro que Antonil se preocupava muito com a evangelização de toda pessoa pertencente ao sistema dos engenhos ${ }^{26}$. Na sua visão religiosa, esses lugares não hospedavam apenas o processo de produção e purgação do açúcar, mas, também, o processo, frente ao paganismo dos escravos, de purgação dos velhos pecados, conversão cristã e produção de novas almas ${ }^{27}$.

Contudo, as questões espirituais não são as únicas que ele analisa, pois as suas dicas se relacionam também com as necessidades materiais dos indivíduos empregados nos engenhos - "o que pertence ao sustento, vestido, \& moderaçaõ do trabalho" ${ }^{\prime \prime 2}$ - as quais devem ser satisfeitas com paternalismo e caridade cristã. Trata-se, com certeza, na perspectiva de Antonil, de um paternalismo pragmático e de uma caridade utilitarista, instrumentos concebidos como funcionais à sobrevivência dos escravos e então à produção açucareira.

Ao escravo, por consequência, "deve o senhor de justiça dar sufficiente alimento, mezinhas na doença, \& modo com que decentemente se cubra \& vista", moderando o ciclo produtivo "de sorte que naõ seja superior ás forças dos que trabalhaõ"; essas palavras parecem então atenuar as disposições prescritas no antigo ditado colonial de derivação bíblica, segundo o qual o escravo só precisaria de "tres PPP, a saber Pao, Paõ, \& Panno"29. Os castigos, nesse contexto, devem ser dados com misericórdia, evitando punir "com impeto, com animo vingativo, por maõ propria, \& com instrumentos terriveis"; ao invés, aos escravos o senhor deve atuar "como pay, dando-lhes o necessario para o sustento, \& vestido, \& algum descanço no trabalho" ${ }^{\prime \prime 30}$. Além disso, para evitar que permaneçam "desconsolados, \& melancolicos, de pouca vida, \&

\footnotetext{
${ }^{26}$ Antonil foi mestre dos noviços e por duas vezes reitor do colégio de Salvador, secretário de vários padres provinciais e ele mesmo provincial da Bahia, entre 1706 e 1709: ver LEITE, Serafim. História da Companhia de Jesus no Brasil. v. 8. Rio de Janeiro: Instituto Nacional do Livro, 1949, p. 45-54. As notícias sobre a vida de Antonil antes da sua entrada na Companhia de Jesus e da sua viagem para o Brasil, assim como sobre a sua família, podem ser reconstruídas a partir das informações conservadas no Archivio di Stato di Lucca (ASL), Indice di Testamenti, n. 14-15.

${ }^{27}$ MELLO E SOUZA, Laura de. O diabo e a Terra de Santa Cruz. Feitiçaria e religiosidade popular no Brasil colonial. São Paulo: Companhia das Letras, 1986, p. 35-44: "A transparência da analogia entre o purgatório de almas e o purgatório do açúcar não deixa sombra de dúvida: homogeneizar a população através da catequese e produzir gêneros rentáveis no mercado externo eram as duas grandes modalidades purgatórias do mercado colonial".

${ }^{28}$ ANTONIL. Op. cit., p. 25.

${ }^{29}$ Ibid., p. 25-26. Esta frase reflete o famoso versículo do Eclesiástico, 33:25 ("Cibaria et virga et onus asino; panis et disciplina et opus servo"), utilizado também pelo jesuíta italiano Jorge Benci ("Para o asno, forragem, chicote e carga; para o servo, pão, correção e trabalho") na sua obra intitulada Economia cristã dos senhores no governo dos escravos, que saiu à luz em Roma em 1705: PIMENTEL, Maria do Rosário. Sob o signo do pecado. Jorge Benci e as normas de convivência entre senhores e escravos na sociedade colonial brasileira. Cadernos de História. Belo Horizonte, v. 7, n. 8, p. 29-45, 2005; BITTENCOURT, Ana Palmira. A economia cristã dos senhores no governo dos escravos: uma proposta pedagógica jesuítica simultânea para os senhores e escravos. Cadernos de Pesquisa. Salvador, v. 3, p. 187-210, 1999.
}

${ }^{30}$ ANTONIL. Op. cit., p. 27. 
saude", é também oportuno deixar que eles comemorem, "em alguns dias do anno", as próprias festas e os próprios "folguedos", os quais representam "o unico alivio do seu cativeiro"31.

Diante dessa lista de conselhos e advertências, para os senhores que não respeitem todas essas obrigações morais, para os senhores que se desinteressem totalmente das condições espirituais e materiais dos próprios escravos, desobedecendo também às relativas prescrições do governo português, Antonil ameaça a punição inflexível das leis divinas, propostas com base no que diz a Bíblia:

Porèm naõ lhes dar farinha, nem dia para a plantarem; \& querer que sirvaõ de sol a sol no partido, de dia \& de noyte com pouco descanço no engenho: como se admittirá no Tribunal de Deos sem castigo? Se o negar a esmola a quem com grave necessidade a pede é negalla a Christo Senhor nosso, como elle o diz no Evangelho; que será negar o sustento \& o vestido ao seu escravo? E que razaõ dará de si quem dá serafina, \& seda, \& outras galas ás que saõ occasiaõ da sua perdição, \& depois nega quatro ou cinco varas de algodaõ, \& outras poucas de panno da serra, a quem se derrete em suor para o servir, \& apenas tem tempo para buscar huma raiz, \& hum caranguejo para comer? E se em cima disto o castigo for frequente, \& excessivo; ou se iraõ embora, fugindo para o matto; ou se mataraõ per si, como costumaõ, tomando a respiraçaõ, ou enforcando-se; ou procuraraõ tirar a vida aos que lha daõ tam mà, recorrendo (se for necessario) a artes diabolicas; ou clamaraõ de tal sorte a Deos que os ouvirá, \& fará aos senhores o que já fez aos Egypcios, quando avexavaõ com extraordinario trabalho aos Hebreos, mandando as pragas terriveis contra suas fazendas, \& filhos, que se lem na sagrada Escritura: ou permittirá que, assim como os Hebreos foraõ levados cativos para Babylonia em pena do duro cativeiro que davaõ aos seus escravos; assim algum cruel inimigo leve esses senhores para suas terras, para que nellas experimentem quam penosa é a vida que elles deraõ, \& daõ continuamente aos seus escravos $^{32}$.

\section{A legitimidade da escravidão segundo Antonil}

No curso de toda a obra, tem um assunto que Antonil nunca questiona: o da natureza, da origem e da licitude da escravidão, que para ele representa uma situação de facto, imanente e inelutável, então legítima; a escravidão existe e é necessária para a produção do açúcar; por consequência, não tem outro predicado que se Ihe deva atribuir. Para o jesuíta italiano, nesse contexto,

\footnotetext{
${ }^{31}$ ANTONIL. Op. cit., p. 28.

${ }^{32}$ Ibid., p. 26-27.
} 
a verdadeira preocupação é outra, ou seja, estabelecer como o senhor deve se comportar diante dos seus escravos para que o engenho seja rentável ${ }^{33}$.

Nesse sentido, o discurso de Antonil não é muito diferente do discurso do seu colega e compatriota Jorge (Giorgio) Benci, que justificava a escravidão como produto indireto do Pecado Original, do qual se produziram as dissensões e as guerras no mundo, por sua vez responsáveis pela submissão natural dos vencidos aos vencedores e pelos relativos sofrimentos ${ }^{34}$. No contexto cultural do pensamento jesuítico e mais geralmente católico, baseado no direito natural tomista de origem escolástica, a legitimidade da escravidão raramente foi discutida durante a Idade Moderna, pois ela era justificada em virtude de ser funcional para o sistema de produção colonial ${ }^{35}$.

A esse respeito, a posição de Antonil e Benci era menos problemática que aquela dos famosos colegas Manuel da Nóbrega, José de Anchieta (figura muito admirada, contudo, por Antonil ${ }^{36}$ ) e Antônio Vieira, sobretudo frente à questão da legitimidade da escravidão dos nativos, geralmente circunscrita aos casos previstos pela lei civil, a saber, como resultado de "guerras justas", de comutações da pena de morte ou de situações de necessidade extrema. Nesse sentido, Antonil e Benci tiveram um papel fundamental, juntos ao padre provincial Alexandre de Gusmão e ao governador-geral António Luís da Câmara Coutinho, contribuindo à redação de uma importante convenção sobre a utilização da mão de obra indígena na Capitania de São Paulo: o texto que eles propuseram não visava legalizar a escravidão dos nativos (os "gentios da terra"), mas previa que os senhores pudessem explorar o seu trabalho e retribuí-lo com equidade, garantindo também a própria assistência para a sua educação civil e religiosa; tais propostas foram aprovadas por Dom Pedro II em 1696, apesar dos protestos apresentados pelo padre Vieira (naquela época o

33 VAINFAS, Ronaldo. Ideologia \& escravidão. Os letrados e a sociedade escravista no Brasil Colonial. Petrópolis: Vozes, 1986, p. 95-103, 135-152; BOSI, Alfredo. Dialética da colonização. 3. ed. São Paulo: Companhia das Letras, 1996, p. 161-163; SOUZA, Ricardo Luiz de. Antonil e a escravidão sem mistérios. História \& perspectivas. Uberlândia, n. 29-30, p. 239-253, 2004; MENDES, Claudinei Magno Magre. Religião e economia em Antonil. Revista Brasileira de História das Religiões. São Paulo, n. 7, p. 3-19, 2010.

${ }^{34}$ PIMENTEL, Maria do Rosário. Sob o signo do pecado. Jorge Benci e as normas de convivência entre senhores e escravos na sociedade colonial brasileira. Cadernos de História. Belo Horizonte, v. 7, n. 8, p. 29-45, 2005; MENDES, Claudinei Magno Magre. Religião e educação em Antonil e Benci. In: OLIVEIRA, Terezinha (Org.). Religiosidade e educação na história. Maringá: Eduem, 2010, p. 69-81.

${ }^{35}$ QUEIRÓS MATTOSO, Kátya de. Ser escravo no Brasil. São Paulo: Brasiliense, 1982, p. 98-116; EISENBERG, José. As missões jesuíticas e o pensamento político moderno. Encontros culturais, aventuras teóricas. Belo Horizonte: Editora UFMG, 2000, p. 146-169; SCHWARTZ, Stuart B. Escravos, roceiros e rebeldes. Bauru: Edusc, 2001, p. 89-94.

${ }^{36}$ Nesse sentido, Cultura e opulência do Brasil foi oferecida por Antonil "aos que desejaõ ver glorificado nos altares ao veneravel padre Joseph de Anchieta", para estimulá-los a contribuir às despesas para o seu processo de beatificação, naquela época ainda parado em Roma por falta de recursos financeiros: ver a introdução de Andrée Mansuy Diniz Silva a ANTONIL, André João. Cultura e opulência do Brasil por suas drogas e minas. São Paulo: Edusp, 2007, p. 34-35. 
principal adversário de Antonil e Benci dentro do colégio baiano ${ }^{37}$ ), segundo 0 qual essa convenção não poderia tutelar adequadamente a liberdade indígena ${ }^{38}$.

Antonil teve um papel fundamental também na revisão dos atos do sínodo da Bahia de 1707, que deram origem a uma compilação normativa fundamental para a arquidiocese local e, de forma mais ampla, para a administração eclesiástica do Brasil. Trata-se das Constituições Primeiras do Arcebispado da Bahia, um conjunto de cinco livros por meio dos quais a vida religiosa local foi regulamentada do ponto de vista pastoral e moral. Nessa compilação, redigida sob a direção do arcebispo Sebastião Monteiro da Vide, foi também especificado o estatuto jurídico dos escravos como membros da comunidade cristã, evidenciando os direitos e os deveres que eles tinham que ter perante a Igreja católica; várias considerações a este respeito foram tiradas, além das ideias de Antonil, mesmo das opiniões de Benci, que permaneceu uma figura de referência para a elaboração do texto final ${ }^{39}$.

\footnotetext{
${ }^{37}$ Sobre as complexas relações entre Antonil e Benci, de um lado, e Vieira, do outro, e sobre suas diferenças na concepção da escravidão, entendida respectivamente como produto do direito natural e do direito positivo, ver: VAINFAS, Ronaldo. Ideologia \& escravidão. Os letrados e a sociedade escravista no Brasil Colonial. Petrópolis: Vozes, 1986, p. 70-88; BOSI, Alfredo. Dialética da colonização. 3. ed. São Paulo: Companhia das Letras, 1996, p. 119-148; MENEZES, Sezinando Luiz. O Padre Antônio Vieira, a cruz e a espada. Maringá: Eduem, 2000, p. 111-123; BITTENCOURT, Ana Palmira. Quatro Visões do Escravismo Colonial: Jorge Benci, Antônio Vieira, Manuel Bernardes e João Antônio Andreoni. Politeia: história e sociedade. Vitória da Conquista, v. 1, n. 1, p. 141-159, 2001; BIVAR MARQUESE, Rafael de. Feitores do corpo, missionários da mente. Senhores, letrados e o controle dos escravos nas Américas, 1660-1860. São Paulo: Companhia das Letras, 2004, p. 11-15, 80-84; FILGUEIRAS, Fernando. O cabedal das virtudes. André João Antonil, a continuidade e a mudança no pensamento jesuíta do brasil setecentista. Revista Intellectus. Rio de Janeiro, v. 1, p. 1-18, 2005; AMBIRES, Juarez Donizete. Antônio Vieira e Antonil: práticas e representações na América portuguesa. Projeto história. São Paulo, n. 37, p. 95-114, 2008; SOARES PESSOA, Raimundo Agnelo. O escravo negro em Antonil e seus contemporâneos. Goiânia: Editora da UCG, 2009, p. 45-99; PO-CHIA HSIA, Ronnie. Jesuit Foreign Missions. A historiographical essay. Journal of jesuit studies. Leiden, n. 1, p. 47-65, 2014. Foi também por causa das dificuldades com o grupo de jesuítas liderado por Vieira que Antonil decidiu assinar-se, no "Proemio" de Cultura e opulência do Brasil, na forma de "O Anonymo Toscano", assim como esconder a própria identidade por meio de um pseudônimo, criando um anagrama quase perfeito a partir do seu verdadeiro nome (de Giovanni Antonio Andreoni para André João Antonil) e colocando na parte final, por meio da letra L de Lucca, uma referência indireta à sua cidade de origem.

${ }^{38}$ As difíceis relações com Vieira não impediram a Antonil de escrever, em 1697, como reitor do Colégio da Bahia, uma carta detalhada sobre o seu falecimento, contando com vários elogios "as principaes ações de sua vida"; esta carta, que permaneceu por muito tempo desconhecida, é seguida pela relação na qual, dois anos mais tarde, Antonil descrevia as virtudes do padre José Suares, velho assistente de Vieira. Os dois documentos foram publicados pelos Annaes da Bibliotheca Nacional do Rio de Janeiro. Rio de Janeiro, v. 19, p. 145-163, 1897. O manuscrito autógrafo da carta sobre a morte de Vieira, intitulado Compendium vitae pereximii patris Antonii Vieyrae, é conservado no Archivum Romanum Societatis Iesu (ARSI), Lusitania, n. 58, II, p. 520-527.

39 MONTEIRO DA VIDE, Sebastião. Constituições primeiras do arcebispado da Bahia. São Paulo: Typographia Antunes, 1853, p. 2-4, 18-25, 37-39, 74-76, 125-126, 145-147, 150-153, 218-222, 293-296, 338-341. A primeira impressão deste texto saiu em Lisboa no ano de 1719. Para uma sua análise detalhada, ver a edição crítica por parte de Bruno Feitler e Evergton Sales Souza, publicada pela Edusp de São Paulo em 2010.
} 


\section{Conclusões}

Considerando que Cultura e opulência do Brasil foi imediatamente censurada pelo governo português, tentar avaliar a real eficácia prática das dicas de Antonil para a administração escravista colonial representa um exercício de pura retórica. Parece mais oportuno fazer-se a pergunta oposta, questionando-se se foram as mesmas modalidades de gestão diária do engenho jesuítico de Sergipe do Conde que afetaram a sua opinião sobre a maneira de governar os escravos. Trata-se de uma dúvida que não pode ser facilmente resolvida, embora os documentos administrativos desse engenho testemunhem que nele eram previstos vários "gastos para alimentação, medicamentos e roupas" dos escravos, conforme as orientações que Antonil queria oferecer por meio da publicação desta obra ${ }^{40}$.

Mais geralmente, redigindo Cultura e opulência do Brasil, ele se propôs a motivar os leitores - em particular, senhores de engenho e lavradores de cana e tabaco - a perseverarem nas próprias atividades agrícolas, que na sua visão paternalista constituíam o elemento central do sistema escravista-patriarcal do Brasil colonial. De certa forma, então, Antonil teria visado evidenciar e justificar os motivos da superioridade social dos senhores de engenho, cujo poder encontrava a própria legitimação no enraizamento local, ou seja, no relacionamento direto com a terra, com as propriedades rurais e com o mundo dos lavradores/escravos.

Nesse sentido, o pensamento político de Antonil, baseado nos tradicionais princípios da "econômica", se manifesta como o espelho de uma posição ideológica surgida durante a Idade Média, por meio do encontro entre cultura clássica e cristianismo militante, do qual se originou um ideal religioso e cavalheiresco que legitimava, na perspectiva de uma missão superior, a preeminência social da nobreza (era o modelo do miles christianus). É uma atitude semelhante à do protagonista - contemporâneo de Antonil - de um dos maiores livros do historiador austriaco Otto Brunner: trata-se do barão Wolf Helmhard von Hohberg, autor da obra Adeliges Landleben (ou Georgica curiosa), um manual enciclopédico dedicado à análise de todo aspecto da economia doméstica e da agricultura, pertencente à assim chamada Hausväterliteratur, gênero literário destinado aos proprietários rurais de língua alemã e à exaltação do papel social da aristocracia fundiária no contexto do Sacro Império Romano-Germânico ${ }^{41}$.

\footnotetext{
${ }^{40}$ Ver a introdução de Andrée Mansuy Diniz Silva a ANTONIL, André João. Cultura e opulência do Brasil por suas drogas e minas. São Paulo: Edusp, 2007, p. 35, onde se faz referência aos documentos conservados no Arquivo Nacional da Torre do Tombo (ANTT), Cartório dos jesuítas, n. $15,17$.

${ }^{41}$ Ver BRUNNER, Otto. Adeliges Landleben und Europäischer Geist. Leben und Werk Wolf Helmhards von Hohberg. 1612-1688. Salzburg: Müller, 1949 (Vita nobiliare e cultura europea. Bologna: il Mulino, 1972, p. 59-227). A obra de Hohberg apareceu em 1682 e teve um grande sucesso, sendo publicada mais quatro vezes entre 1687 e 1715: será que Antonil pôde conhecêla?
} 
É, sem dúvida, uma ligação sugestiva: frente à economia pré-industrial do Antigo Regime, onde a riqueza não valia como tal, mas unicamente no quadro do sistema ético e político da "econômica", as propriedades senhoriais (nas colônias americanas assim como na Europa) constituíam o lugar decisivo do direito de governo e do equilíbrio social, a garantia mais sólida e duradoura da obrigação aristocrática de presença no território e de tutela dos seus moradores. Nesse contexto, então, os interesses dos senhores de engenho do Brasil tinham que ser defendidos; é o que Antonil tentou fazer no curso da sua vida, seguramente por meio das dicas contidas em Cultura e opulência do Brasil (obra que, contudo, foi logo censurada), e talvez mesmo por meio de uma precisa escolha de campo durante a Guerra dos Mascates no Pernambuco, quando ele foi acusado de tomar uma posição muito crítica com respeito às reclamações dos mercadores reinóis, preferindo apoiar as posições da aristocracia açucareira de Olinda ${ }^{42}$.

\section{Sobre o autor}

Matteo Giuli possui graduação com louvor em Letras pela Università di Pisa (2005) e doutorado em História Moderna pela Universitá di Pisa e pela École des Hautes Études en Sciences Sociales de Paris (2010). Entre 2011 e 2013 foi bolsista de pós-doutorado pela Università degli Studi di Siena. Atualmente é bolsista da Capes na Universidade de Brasília com vínculo de pesquisador colaborador pleno. Colabora também com a Yale University no projeto Limited Liability Partnerships in Tuscany from 1445 to 1808. Escreveu vários artigos de história institucional e social com enfoque sobre o contexto político da Itália de Antigo Regime, além de um livro publicado em 2012 pela École française de Rome. E-mail: mattegiuli@gmail.com.

Artigo recebido em 29 de janeiro de 2015. Aprovado em 23 de agosto de 2016.

\footnotetext{
${ }^{42}$ Capistrano de Abreu, contudo, parece não acreditar nessas acusações, pois ele escreve que Antonil "era provincial ao rebentar a guerra dos Mascates; ha queixas, provavelmente fideindignas, de haver manifestado sympathias a favor da nobreza de Olinda": ABREU, João Capistrano de. Capítulos de história colonial (1500-1800). Rio de Janeiro: Orosco\&C., 1907, p. 162-163.
} 